\title{
Abnormal Cellular Repolarization due to Implantable Cardioverter Defibrillator Shock: A Case Report
}

\author{
Andrea Campana $^{\mathrm{a}, \mathrm{c}}$, Arturo Granato ${ }^{\mathrm{b}}$, Nicola Rovai ${ }^{\mathrm{b}}$, Giuseppe Di Benedetto ${ }^{\mathrm{a}}$
}

\begin{abstract}
Implantable cardioverter-defibrillators (ICDs) have a considerable impact on the therapy of patients with threatening ventricular arrhythmias, significantly reducing the risk of sudden death. Even though newest devices have achieved a remarkable reliability, the delivery of inappropriate shocks is still possible. In this paper a singular case of T-wave oversensing is described, associated with a high number of inappropriate shocks and consequent rapid depletion of ICD battery. Persistent abnormalities of cellular repolarization following a first appropriate shock were believed to be at the origin of T-wave oversensing.
\end{abstract}

Keywords: ICDs; T-wave oversensing; Inappropriate shocks; Battery depletion; Remote monitoring

\section{Introduction}

Despite the proven benefits of therapy with implantable cardioverter-defibrillators (ICDs) in primary and secondary prevention of sudden cardiac death [1], a relatively common adverse effect is represented by inappropriate shocks, due both to atrial arrhythmias with rapid ventricular conduction and, less frequently, to sensing abnormalities. Inappropriate shocks may cause physical pain, resulting in worsening of patients' quality of life and paving the way, in some cases, to mental disorders [2]; moreover, they may also be arrhythmogenic "per se" [3]. Inappropriate shocks are more common in patients with a history of atrial fibrillation, diastolic hy-

\footnotetext{
Manuscript accepted for publication December 18, 2013

${ }^{a}$ Heart Department A.O.U. "S.Giovanni di Dio e Ruggi d'Aragona", Salerno, Italy

${ }^{\mathrm{b}}$ Biotronik Italia S.p.a., Milan, Italy

'Corresponding author: Andrea Campana, Heart Department, A.O.U. "S.Giovanni di Dio e Ruggi d'Aragona", Largo Citta di Ippocrate 1, 84131 Salerno, Italy. Email: acampana.sa@alice.it
}

doi: http://dx.doi.org/10.14740/jmc1642w pertension, previous appropriate shocks and in smokers; indeed, about $16 \%$ of inappropriate shocks are caused by atrial fibrillation (AF) or supraventricular tachycardias (SVTs) [4]. The growing use of remote monitoring in the follow-up of ICDs may allow an early detection of anomalous signals on intracardiac electrograms (IEGMs) that could lead to a false detection of ventricular fibrillation (VF) [5].

As shown by several case reports, lead failures can be promptly and reliably detected by remote monitoring; usually, lead failures don't immediately cause an inappropriate shock but the occasional discovery of noise artefacts, detected as self-terminating VF episodes, may anticipate the first inappropriate shock of hours or even days [5]: these warnings are very helpful to adopt corrective measures in order to avoid any inappropriate therapies.

\section{Case Report}

A 67-year-old female, with valvular cardiomyopathy and permanent atrial fibrillation (PAF), who was implanted in 2011 with a single-chamber ICD (Biotronik Lumax 300 VR$\mathrm{T})$ and on remote monitoring with Biotronik Home Monitoring $^{\circledR}$ system (HM), came to our emergency room because of a series of shocks delivered by the ICD in the previous hours; she was rapidly admitted to the Coronary Care Unit (CCU) and put on continuous electrocardiographic monitoring. The ICD interrogation, showed the depletion of ICD battery (state of "End of Service" with active anti-brady therapy and VT/ VF detection disabled): this condition had been provoked by the delivery of 84 shocks and 44 capacitors charges with aborted shock (Fig. 1), occurred in VF detection zone. The ICD was programmed with a VT detection zone between 170 and 200 b.p.m., treated with two Antitachycardia pacing (ATP) therapies before multiple shocks at the maximum energy. The VF detection zone was programmed to start above 200 b.p.m. and treated with a single ATP (for Fast VT) and eight shocks at the maximum energy.

At first sight, IEGMs analysis seemed to show that all the shocks had been inappropriate, due to noise detection, probably generated by lead failure (Biotronik Linox Smart SD 65-16, double-coil with active fixation); nevertheless, it 


\begin{tabular}{|c|c|c|c|c|c|c|c|c|c|c|c|}
\hline N. & Date-hour & $\mid$\begin{tabular}{|c|} 
Energia \\
{$\left[{ }^{2}\right]$}
\end{tabular} & $\begin{array}{l}\text { Charging } \\
\text { Time [s] }\end{array}$ & \begin{tabular}{|l|} 
Inped. \\
{$[\Omega]$}
\end{tabular} & Description & N. & | Date-hour | & \begin{tabular}{|c} 
Energio \\
{$[\mathrm{J}]$}
\end{tabular} & $\begin{array}{l}\text { Charging } \\
\text { Time }[\mathrm{s}]\end{array}$ & \begin{tabular}{|c|} 
Inped. \\
{$[\Omega]$}
\end{tabular} & Description \\
\hline 233 & 07:04 & 30 & 8.3 & 39 & & $\mid 303$ & $30 / 12 / 1208: 48$ & 30 & *** & $* * *$ & Abor to \\
\hline $\begin{array}{l}232 \\
231\end{array}$ & $\begin{array}{lll}30 / 12 / 12 & 07: 03 \\
30 / 12 / 12 & 07: 01\end{array}$ & 30 & 4.8 & $\approx * * *$ & Termingzinoe senzn shock & $\mid \begin{array}{ll}302 \\
301\end{array}$ & $\left|\begin{array}{l}30 / 12 / 12 \\
3\end{array} 08: 46\right|$ & 30 & 8.3 & 39 & Terninnzinne cenzo shock \\
\hline 230 & 30/12/12 $06: 59$ & 30 & 2.5 & 39 & Ierminazione senza siock & $\mid \begin{array}{ll}301 \\
300\end{array}$ & 30/12/12 08:43 & 30 & 10.4 & 39 & Terhinazione senza snock \\
\hline 229 & $30 / 12 / 1206: 59$ & 30 & 2.8 & $* \approx *$ & & 299 & |30/12/12 08:41 & 30 & 10.4 & 39 & \\
\hline 228 & $30 / 12 / 1206: 57$ & 30 & 3.3 & * & Terninazione senzo shock & ||298 & 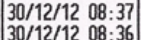 & 30 & 10.3 & 39 & \\
\hline 226 & $\mid \begin{array}{ll}30 / 12 / 12 \\
30 / 12 / 12 & 06: 56\end{array}$ & 30 & 5.4 & 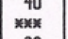 & Terninazione senza shock & $\mid 296$ & 30/12/12 08:34 & 30 & 10.0 & 39 & \\
\hline $\begin{array}{l}225 \\
224\end{array}$ & 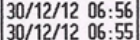 & $\begin{array}{l}30 \\
30\end{array}$ & $\begin{array}{l}8.3 \\
3.3\end{array}$ & $\begin{array}{l}39 \\
41\end{array}$ & Inverso & $\mid \begin{array}{ll}295 \\
294\end{array}$ & $\left|\begin{array}{ll}30 / 12 / 12 & 08: 32 \\
30 / 12 / 12 & 08: 30\end{array}\right|$ & $\begin{array}{l}30 \\
30\end{array}$ & 9.9 & 39 & \\
\hline 223 & 30/12/12 $06: 55$ & 30 & 4.9 & $x \in=$ & Terninazione senza shock & 293 & $30 / 12 / 1208: 28$ & 30 & 2.0 & $x \in x$ & Terninazione senza shock \\
\hline $\begin{array}{l}222 \\
221\end{array}$ & $\begin{array}{lll}30 / 12 / 12 & 06: 52 \\
30 / 12 / 12 & 06: 49\end{array} \mid$ & $\begin{array}{l}30 \\
30\end{array}$ & $\begin{array}{l}8.3 \\
1.5\end{array}$ & $\begin{array}{l}40 \\
41\end{array}$ & & |292 & $\left|\begin{array}{lll}30 / 12 / 12 & 08: 26 \\
30 / 12 / 12 & 08: 26\end{array}\right|$ & 30 & $\begin{array}{l}3.8 \\
1.5\end{array}$ & $\begin{array}{r}39 \\
x * 0 *\end{array}$ & Terninazione senza shock \\
\hline 220 & $30 / 12 / 1206: 49$ & 30 & 6.8 & 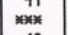 & Terninazione senza shock & $\mid 290$ & 30/12/12 $08: 24$ & 30 & 2.8 & wax & Terninazione senza shock \\
\hline 219 & $30 / 12 / 1206: 47$ & 30 & 8.3 & 40 & Inverso & 289 & $30 / 12 / 1208: 23$ & 30 & 1.9 & sex & Terninazione senza shock \\
\hline$\left[\begin{array}{ll}218 \\
217\end{array}\right.$ & $\left|\begin{array}{ll}30 / 12 / 12 & 06: 47 \\
30 / 12 / 12 & 06: 47\end{array}\right|$ & 30 & $\begin{array}{l}3.5 \\
4.5\end{array}$ & $\begin{array}{l}40 \\
x \in x\end{array}$ & Terninazione senza shock & $\| 287$ & $\mid \begin{array}{ll}30 / 12 / 12 & 08: 23 \\
30 / 12\end{array}$ & 30 & $\begin{array}{l}4.4 \\
5.3\end{array}$ & *** & Terninazione senza shock \\
\hline 216 & $30 / 12 / 12 \quad 06: 46$ & 30 & 8.1 & 40 & & 286 & $30 / 12 / 1208: 22$ & 30 & 9.9 & 39 & Inverso \\
\hline $\begin{array}{l}215 \\
214\end{array}$ & $\left|\begin{array}{lll}30 / 12 / 12 & 06: 44 \\
30 / 12 / 12 & 06: 42\end{array}\right|$ & $\begin{array}{l}30 \\
30\end{array}$ & $\begin{array}{l}8.1 \\
4.8\end{array}$ & $\begin{array}{l}40 \\
40\end{array}$ & & $\begin{array}{l}285 \\
284\end{array}$ & $\left|\begin{array}{lll}30 / 12 / 12 & 08: 22 \\
30 / 12 / 12 & 08: 22\end{array}\right|$ & 30 & $\begin{array}{l}1.3 \\
8.5\end{array}$ & $\begin{array}{r}41 \\
* * *\end{array}$ & Terninazione senza shock \\
\hline 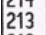 & $30 / 12 / 1206: 42$ & 30 & 3.1 & xex & Terninazione senza shock & $\mid 283$ & 30/12/12 08:21 & 30 & 9.5 & 39 & \\
\hline 212 & $30 / 12 / 12 \quad 06: 40$ & 30 & 8.1 & 40 & & 282 & $30 / 12 / 1208: 20$ & 30 & 5.3 & 40 & \\
\hline 211 & 30/12/12 06:36 & 30 & 8.1 & 40 & & ||281 & $\left|\begin{array}{l}30 / 12 / 12 \\
301212\end{array} 08: 20\right|$ & 30 & $\begin{array}{l}3.8 \\
4.8\end{array}$ & 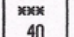 & Terninazione senza shock \\
\hline 2209 & 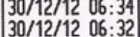 & 30 & 8.0 & 41 & & 279 & 30/12/12 08:16 & 30 & 5.8 & $* * 0$ & Terninazione senza shock \\
\hline 208 & 30/12/12 $06: 31$ & 30 & 3.9 & 40 & & 278 & $30 / 12 / 12 \quad 08: 13$ & 30 & 9.3 & 39 & \\
\hline 207 & $30 / 12 / 1206: 29$ & 30 & 4.9 & $\mid \begin{array}{ll}x \in x \\
40\end{array}$ & Terninazione senza shock & || 277 & $\left|\begin{array}{l}30 / 12 / 12 \\
30 / 1212\end{array} 08: 12\right|$ & 30 & 9.3 & 39 & \\
\hline 206 & $\mid \begin{array}{l}30 / 12 / 12 \\
301212\end{array} 06: 28$ & $\begin{array}{l}30 \\
30\end{array}$ & $\begin{array}{l}8.1 \\
8.0\end{array}$ & 40 & Inverso & $\mid$\begin{tabular}{|l|l|l|}
276 \\
275
\end{tabular} & 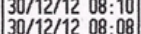 & 30 & $\begin{array}{l}7.4 \\
1.8\end{array}$ & xeox & Terninazione senza shock \\
\hline 204 & 30/12/12 $06: 27$ & 30 & 6.8 & 41 & & 274 & $30 / 12 / 1208: 07$ & 30 & 4.3 & 41 & \\
\hline & $30 / 12 / 1$ & 30 & 1.1 & 我茲 & Terninazione senza shock & 273 & $30 / 12 / 12 \quad 08: 07$ & 30 & 4.6 & $\approx * \approx$ & Terninazione senza shock \\
\hline 202 & $30 / 12 /$ & 30 & 1.0 & 41 & & $272>272>0$ & $30 / 12 / 120$ & 30 & 1 & 39 & \\
\hline 201 & 30/12/12 06:24 & 30 & 7.1 & x*a & Terninazione senza shock & 271 & $30 / 12 / 12$ 08:0 & 30 & 9. & 39 & \\
\hline & 30/12/12 06:24 & 30 & $\begin{array}{l}6.0 \\
18\end{array}$ & $\begin{array}{c}40 \\
* 0 * 0\end{array}$ & Terninazione senza shock & $\mid \begin{array}{ll}270 \\
269\end{array}$ & 30/12/12 08:02 & 30 & 9.0 & 39 & \\
\hline 198 & $\begin{array}{lll}300 / 12 / 12 & 06: 24 \\
30 & 06: 21\end{array}$ & 30 & 2.1 & 41 & Senka MIOLA & 268 & $\begin{array}{l}30 / 12 / 12 \\
307: 59\end{array}$ & 30 & 2.3 & 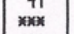 & Terninazione senza shock \\
\hline & 30/12/12 $06: 21$ & 30 & 5.6 & *ax & Terninazione senza shock & 267 & $30 / 12 / 12 \quad 07: 58$ & 30 & 8.9 & 39 & \\
\hline 196 & $30 / 12 / 12$ 06:21 & 30 & 6.3 & 41 & & 266 & $30 / 12 / 1207: 57$ & 30 & 8.9 & 39 & \\
\hline 195 & 30/12/12 06:20 & 30 & 1.5 & 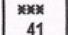 & Terninazione senza shock & 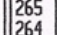 & 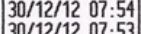 & 30 & 7.1 & 39 & Terninazione senza shock \\
\hline 193 & $30 / 12 / 1206: 18$ & 30 & 7.8 & 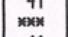 & Terninazione senza shock & $\mid \begin{array}{ccc}267 \\
263\end{array}$ & 30/12/12 $07: 51$ & 30 & 8.8 & 39 & \\
\hline 192 & $30 / 12 / 1206: 17$ & 30 & 6.3 & 41 & & |262 & 30/12/12 $07: 50$ & 30 & 3.0 & 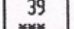 & 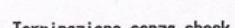 \\
\hline 91 & 30/12/12 06:17 & 30 & 1.5 & $* * *$ & Terninazione senza shock & 261 & 30/12/12 $07: 49$ & 30 & 6.1 & 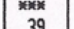 & Terninazione senza shock \\
\hline 190 & 30/12/12 06:16 & 30 & 1.4 & 41 & & & 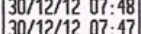 & 30 & 8.8 & 39 & \\
\hline 189 & 30/12/12 06:15 & 30 & $\begin{array}{l}8.0 \\
44\end{array}$ & ${ }_{41}^{* * * *}$ & Terninazione senza shock & 259 & $\mid \begin{array}{l}30 / 12 / 121207.47 \\
30 / 12112\end{array} 07.45$ & $\begin{array}{l}30 \\
30\end{array}$ & $\begin{array}{l}8.8 \\
6.6\end{array}$ & ${ }_{41}^{39}$ & \\
\hline 187 & 30/12/12 06:15 & 30 & $\begin{array}{l}9.9 \\
3.4\end{array}$ & 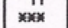 & Terninazione senza shock & 257 & $30 / 12 / 1207: 42$ & 30 & 2.1 & 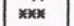 & Terninazione senza shock \\
\hline 186 & 30/12/12 $06: 11$ & 30 & 0.4 & 41 & & & $30 / 12 / 12$ 07:39 & 30 & & 40 & \\
\hline 185 & 30/12/12 06:11 & 30 & 8.0 & 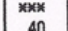 & Terninazione senza shock & 54 & 30/12/12 $07: 37$ & 30 & 2 & 39 & 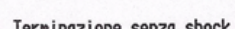 \\
\hline $\mid \begin{array}{l}184 \\
183\end{array}$ & $\begin{array}{l}30 / 12 / 121206: 06: 11 \\
30 / 12 / 12 \\
06: 10\end{array}$ & 30 & 7.9 & 40 & Invers & $\mid \begin{array}{lll}254 \\
253\end{array}$ & 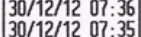 & 30 & $\begin{array}{l}2.6 \\
6.3\end{array}$ & 40 & Ferninazione sem \\
\hline T & 30/12/12 06:09 & 30 & 5.3 & $x \in x$ & Terninazione senza shock & 252 & $30 / 12 / 12 \quad 07: 32$ & 30 & 2.5 & nex & Terninazione senza shock \\
\hline 81 & $30 / 12 / 1206: 08$ & 20 & 5.5 & 41 & & $\mid 251$ & 30/12/12 07:32 & 30 & 5.8 & 41 & \\
\hline 80 & & & 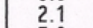 & $n$ & Terninazione senza shock & 250 & 30/12/12 07:31 & 30 & 2.8 & **** & Terninazione senza shock \\
\hline II) & $30 / 12$ & O & 7.9 & & & & $\mid \begin{array}{l}30 / 12 / 12 \\
307: 30\end{array}$ & & 8.5 & 40 & \\
\hline 1778 & $\begin{array}{llll}30 / 12 / 12 & 06: 05 \\
30 / 12 / 12 & 06: 04\end{array}$ & $\begin{array}{l}30 \\
30\end{array}$ & $\begin{array}{l}3.5 \\
4.1\end{array}$ & 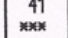 & Terninazione senza shock & 247 & $\mid \begin{array}{l}30 / 12 / 12 / 12 \\
307: 28\end{array}$ & 30 & 2.8 & 39 & \\
\hline & 30/12/12 06:04 & & & & & 246 & $30 / 12 / 1207: 26$ & 30 & 6.3 & 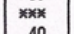 & Terninazione senza shock \\
\hline & & & & & & 244 & $30 / 121$ & 30 & 8.5 & 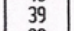 & \\
\hline \multirow{7}{*}{\multicolumn{6}{|c|}{ Termination without shock }} & $\begin{array}{l}243 \\
242\end{array}$ & $\mid \begin{array}{l}30 / 12 / 12 \\
301212\end{array} 07: 20$ & 30 & 8.4 & 39 & \\
\hline & & & & & & & 30112 & 30 & & 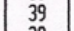 & \\
\hline & & & & & & $\begin{array}{l}240 \\
239\end{array}$ & 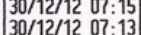 & 30 & 8.4 & 39 & \\
\hline & & & & & & 而 & $30 / 12 / 12$ 07:12 & & & & \\
\hline & & & & & & 237 & 10 & 30 & 11 & & \\
\hline & & & & & & 236 & $\begin{array}{l}30 / 12 / 12 \\
30 / 12 / 12\end{array} 07: 09$ & 30 & 6 & 40 & \\
\hline & & & & & & 234 & 30/12/12 $07: 06$ & & & $* * * *$ & Terninazione senza shock \\
\hline
\end{tabular}

Figure 1. Part of the episodes recorded in the memory of Biotronik Lumax $300 \mathrm{VR}-\mathrm{T}$; from episode number 176 (30th December 2012 at 06:04 a.m.) to episode number 303 (30th December 2012 at 08:48 a.m.).

was immediately clear that noise signals were mainly concentrated on the T-waves. A more careful examination of IEGMs and HM reports, highlighted how the first shock had been appropriately delivered on the occasion of a true episode of VF, triggered by a premature ventricular complex (PVC) after a long RR cycle (Fig. 2A); soon after, in a rapid sequence, several VF events were inappropriately detected, caused by "oversensing" of artefacts located on T-waves (Fig. 2B), leading to a such great number of therapies to cause the depletion of battery.

Laboratory tests performed in the CCU showed only a moderate hypokalemia $\left(\mathrm{K}^{+}=2.8 \mathrm{mEq} / \mathrm{L}\right)$, probably involved in the genesis of the arrhythmia that caused the first shock; the IEGMs real-time analysis carried out at bedside, highlighted the persistence of $\mathrm{T}$ waves abnormal detection both in spontaneous and paced beats (Fig. 3).

Moreover, the examination of previous HM reports, documented the absolute normality of an IEGM received five days before the "electrical storm", with ventricular activity properly and clearly detected (Fig. 4), without T-waves artefacts oversensing.

Therefore, it was clear that the appearance of "anomalous signals" focused on the T-waves and their inappropriate detection by the ICD had been subsequent to the first ap- 


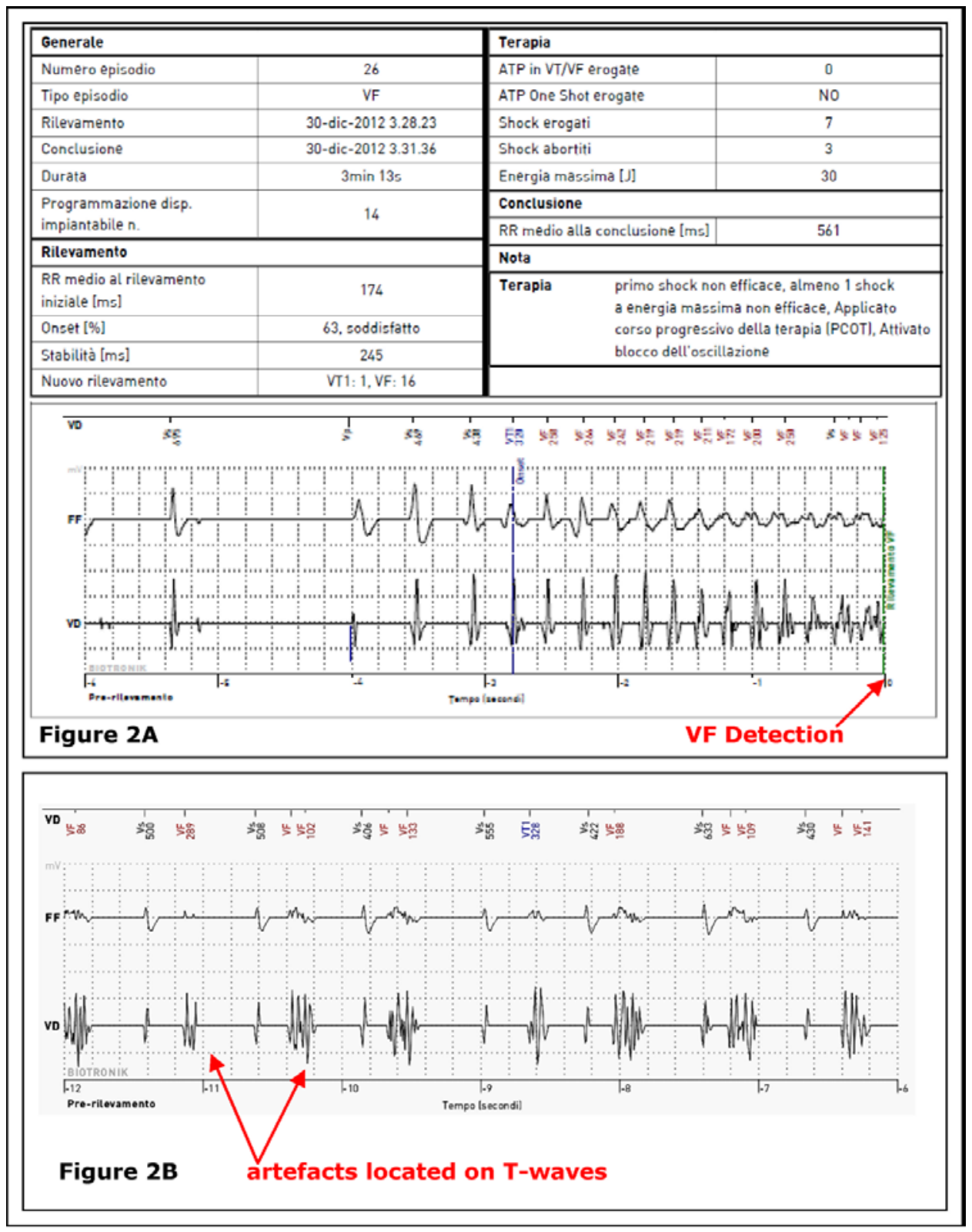

Figure 2. Section A: BIOTRONIK Home Monitoring ${ }^{\circledR}$ IEGM (report \# 26): onset of a real ventricular fibrillation, at the origin of the first shock, on 30th December 2012 at 03:28 a.m. Section B: BIOTRONIK Home Monitoring ${ }^{\circledR}$ IEGM (report \# 34) inappropriate detection of ventricular fibrillation event due to anomalous signals focused on T-waves.

propriate shock. The device was replaced on the third day of hospitalization with a Biotronik single chamber ICD (Lumax 300 VR-T). During the procedure, all standard tests able to unmask a lead fracture have been performed (for example, pacing with high voltage impulse). No lead failure was detected. Electrical analysis of the lead showed good pacing threshold and impedance, but still documented the presence of abnormal signals in the context of T-waves.

The problem would have been potentially overcome by using the T-Wave Suppression algorithm (TWS ${ }^{\text {TM}}$ ); however, we chose to implant a new ventricular lead (Biotronik Linox
Smart S 65, single coil with active fixation), positioning the tip on the mid-septum: electrical measurements proved to be optimal, and most important, there was no trace of anomalous T-wave signals; no drug, potentially able to avoid oversensing, was given to the patient.

\section{Discussion}

ICDs have a considerable impact on the treatment of patients with potentially harmful ventricular arrhythmias, significant- 


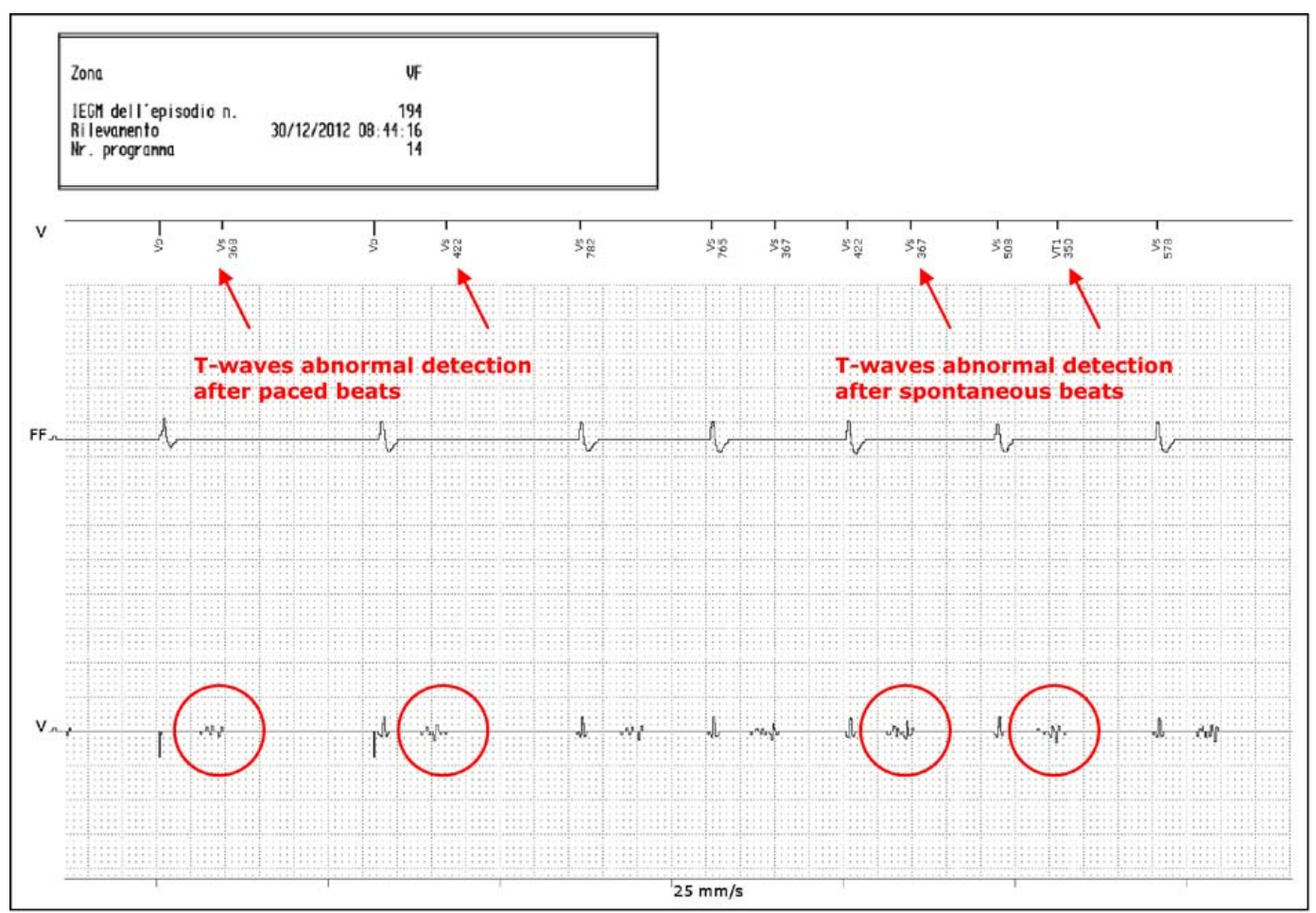

Figure 3. IEGM via Renamic ${ }^{\circledR}$ programmer during the patient's stay in CCU: evidence of abnormal detection of T waves.

ly reducing the risk of sudden death [6-8]. A tumultuous development in technology has changed the devices from relatively simple and non-programmable, to complex units with multiple options for detection and treatment of tachyarrhythmia. Even though these systems have achieved a remarkable reliability, some problems may still occur, including the possible delivery of inappropriate shocks. Despite dual chamber sensing and the introduction of specific algorithms based on the analysis of rate "onset" and "stability", or on QRS morphology, all of which have improved the discrimination capability [9], SVTs remain the most common cause of inappropriate shocks: indeed, even in patients with dual chamber ICDs it is still possible that inappropriate shocks may happen [10]. Inappropriate ICD discharges may also result from extracardiac signals like electromagnetic interference (EMI) and electric fields or leakage currents from domestic or medical electrical devices: all these extracardiac signals and signals coming from damaged or improperly connected leads can mimic VT and/or VF [11]. In a recent paper [12], Powell et al concluded that external noise and lead/connector noise are the primary factors resulting in ICD inappropriate shocks: in this particular list, T-wave oversensing results to be the last common cause $(2 \%)$; furthermore, the authors report that noise/artefacts decrease immediately after an inappropriate shock in nearly half of the episodes: this is exactly the opposite compared with the present case. Several mechanisms are involved in multiple counting of T-wave: drugs, hyperkalemia, alcohol, hyperglycemia or changes in the morphology of IEGMs $[13,14]$. It could be sometimes possible to overcome this problem by setting a lower sensitivity or a longer refractory period, but these measures could compromise the ICD's capability of discriminating arrhythmias [14]. A key factor in our case-report is the appearance of artefacts on the ventricular channel after the delivery of an appropriate shock. The data analysis led us to believe that the phenomenon was not lead-related, because the "abnormal signals" were always focused on T-waves and were not present in other phases of the cardiac cycle. Furthermore, during device replacement, electrical measures were absolutely normal and comparable to those recorded in follow up visits and disclosed in the HM reports. Therefore, it seemed that the reasons were presumably to be found in the boundary of myocardial tissue; an absolutely speculative hypothesis may refer to the effect of an electric field on the repolarization of cellular action potential (AP) when the field is applied during the refractory period, as described by Knisley in the rabbit papillary muscles [15]. This effect may be explained through basic membrane mechanisms, such as voltage and time-dependent ionic currents; changes in transmembrane potentials should be probably induced by the application of a strong electrical stimulus, so modifying ionic currents over an indeterminate time. Thus, an electric field of a remarkable magnitude (for example an ICD shock) could cause localized reentry, due to anisotropy and prolongation of cellular refractoriness. A validation of this hypothesis comes from the data of Kodama about the arrhythmogenic effects of a 


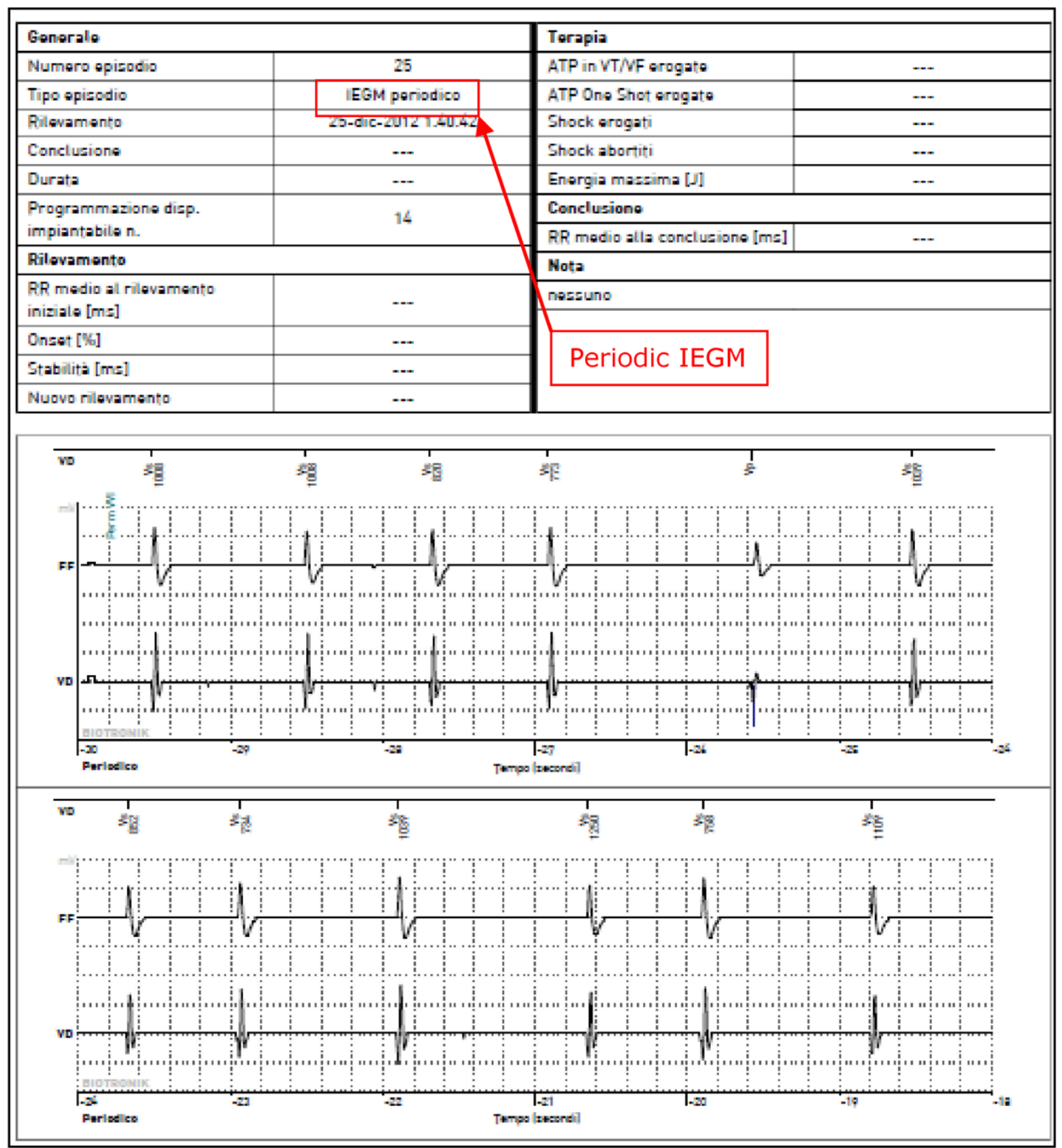

Figure 4. BIOTRONIK Home Monitoring ${ }^{\circledR}$ periodic IEGM on 25th December 2012 (report \# 25), showing ventricular activity properly detected.

DC shock on the rabbit cardiac cells, represented by action potential lengthening and dispersion of refractoriness: moreover, these effects seem to be more evident in the right ventricle cells [16].

Therefore, the occurrence of artefacts on T-waves after a first ICD appropriate shock might have been the expression of a persistent alteration of cellular repolarization. It is also conceivable that changes in myocardial tissues were localized in an area surrounding the tip of the lead, because the "anomalous signals" were not present in the area of new implanted lead.

There are several reports regarding inappropriate ICDs shocks due to T-wave oversensing, but we believe that this case has peculiar characteristics. Beyond the proposed hypothesis to explain the phenomenon of "abnormal signals" focused on T-waves and ascribed to persistent abnormalities of cellular repolarization, we are not aware of other cases in which $\mathrm{T}$-wave oversensing resulted in such a high number of 
inappropriate shocks to cause a so fast depletion of device battery.

\section{Conflict of Interest Disclosure}

A. Granato and N. Rovai belong to technical staff of Biotronik Italia S.p.A. A. Campana and G. Di Benedetto: no conflict of interests.

\section{References}

1. Tracy CM, Epstein AE, Darbar D, DiMarco JP, Dunbar SB, Estes NA, 3rd, Ferguson TB, Jr., et al. 2012 ACCF/ AHA/HRS focused update of the 2008 guidelines for device-based therapy of cardiac rhythm abnormalities: a report of the American College of Cardiology Foundation/American Heart Association Task Force on Practice Guidelines and the Heart Rhythm Society. [corrected]. Circulation. 2012;126(14):1784-1800.

2. Schron EB, Exner DV, Yao Q, Jenkins LS, Steinberg JS, Cook JR, Kutalek SP, et al. Quality of life in the antiarrhythmics versus implantable defibrillators trial: impact of therapy and influence of adverse symptoms and defibrillator shocks. Circulation. 2002;105(5):589-594.

3. Luderitz B, Jung W, Deister A, Marneros A, Manz M. Patient acceptance of the implantable cardioverter defibrillator in ventricular tachyarrhythmias. Pacing Clin Electrophysiol. 1993;16(9):1815-1821.

4. Daubert JP, Zareba W, Cannom DS, McNitt S, Rosero SZ, Wang P, Schuger C, et al. Inappropriate implantable cardioverter-defibrillator shocks in MADIT II: frequency, mechanisms, predictors, and survival impact. J Am Coll Cardiol. 2008;51(14):1357-1365.

5. Spencker S, Coban N, Koch L, Schirdewan A, Muller D. Potential role of home monitoring to reduce inappropriate shocks in implantable cardioverter-defibrillator patients due to lead failure. Europace. 2009;11(4):483488.

6. A comparison of antiarrhythmic-drug therapy with implantable defibrillators in patients resuscitated from near-fatal ventricular arrhythmias. The Antiarrhythmics versus Implantable Defibrillators (AVID) Investigators. N Engl J Med. 1997;337(22):1576-1583.

7. Moss AJ, Hall WJ, Cannom DS, Daubert JP, Higgins SL,
Klein $\mathrm{H}$, Levine $\mathrm{JH}$, et al. Improved survival with an implanted defibrillator in patients with coronary disease at high risk for ventricular arrhythmia. Multicenter Automatic Defibrillator Implantation Trial Investigators. N Engl J Med. 1996;335(26):1933-1940.

8. Buxton AE, Lee KL, Fisher JD, Josephson ME, Prystowsky EN, Hafley G. A randomized study of the prevention of sudden death in patients with coronary artery disease. Multicenter Unsustained Tachycardia Trial Investigators. N Engl J Med. 1999;341(25):1882-1890.

9. Boriani G, Occhetta E, Pistis G, Menozzi C, Jorfida M, Sermasi S, Pagani M, et al. Combined use of morphology discrimination, sudden onset, and stability as discriminating algorithms in single chamber cardioverter defibrillators. Pacing Clin Electrophysiol. 2002;25(9):13571366.

10. Swerdlow CD. Supraventricular tachycardia-ventricular tachycardia discrimination algorithms in implantable cardioverter defibrillators: state-of-the-art review. J Cardiovasc Electrophysiol. 2001;12(5):606-612.

11. Occhetta E, Bortnik M, Magnani A, Francalacci G, Marino P. Inappropriate implantable cardioverter-defibrillator discharges unrelated to supraventricular tachyarrhythmias. Europace. 2006;8(10):863-869.

12. Powell BD, Asirvatham SJ, Perschbacher DL, Jones PW, Cha YM, Cesario DA, Cao M, et al. Noise, artifact, and oversensing related inappropriate ICD shock evaluation: ALTITUDE noise study. Pacing Clin Electrophysiol. 2012;35(7):863-869.

13. Koul AK, Keller S, Clancy JF, Lampert R, Batsford WP, Rosenfeld LE. Hyperkalemia induced $\mathrm{T}$ wave oversensing leading to loss of biventricular pacing and inappropriate ICD shocks. Pacing Clin Electrophysiol. 2004;27(5):681-683.

14. Assadian Rad M, Emkanjoo Z, Moladoust H. Hyperglycemia-Induced T-Wave Oversensing as a Cause of Cardiac Resynchronization Therapy (CRT) Failure. J Tehran Heart Cent. 2012;7(1):30-32.

15. Knisley SB, Smith WM, Ideker RE. Effect of field stimulation on cellular repolarization in rabbit myocardium. Implications for reentry induction. Circ Res. 1992;70(4):707-715.

16. Kodama I, Sakuma I, Shibata N, Honjo H, Toyama J. Arrhythmogenic changes in action potential configuration in the ventricle induced by DC shocks. J Electrocardiol. 1999;32(Suppl):92-99. 